\title{
Late diagnosis of 5 alpha steroid-reductase deficiency due to IVS12A>G mutation of the SRD5a2 gene in an adolescent girl presented with primary amenorrhea
}

\author{
Nicos Skordis, ${ }^{1,2}$ Christos Shammas, ${ }^{2}$ Elisavet Efstathiou, ${ }^{1}$ Amalia Sertedaki, ${ }^{3}$ \\ Vassos Neocleous, ${ }^{2}$ Leonidas Phylactou ${ }^{2}$
}

${ }^{1}$ Pediatric Endocrine Unit, Makarios Hospital, Nicosia, Cyprus, ${ }^{2}$ Department of Molecular Genetics Function \& Therapy, The Cyprus Institute of Neurology and Genetics, Nicosia, Cyprus, ${ }^{3}$ Unit of Endocrinology, Diabetes and Metabolism, First Department of Pediatrics, Athens University, Medical School, Athens, Greece

\begin{abstract}
BACKGROUND: The clinical spectrum of $5 \alpha$-reductase deficiency, caused by mutations in the $S R D 5 A 2$ gene, ranges from complete female appearance of the external genitalia at birth to nearly complete male phenotype. CASE REPORT: A 14-year-old girl presented with primary amenorrhea (PA) and lack of breast development. She was $173 \mathrm{~cm}$ in height, had an increased amount of pubic hair and clitoromegaly $(3 \mathrm{~cm})$, with a $4 \mathrm{~cm}$ blind vaginal pouch. Gonads were palpable in the inguinal canal bilaterally and no uterus was identified on ultrasound. Chromosomal analysis showed a 46,XY karyotype. The Testosterone/DHT ratio was high (16.5) and further increased to 29.4 after stimulation with hCG, thus favouring the diagnosis of $5 \alpha$-reductase deficiency. Since the issue of gender change was not considered, gonadectomy was performed followed by successful feminisation with hormonal replacement therapy. GENETIC STUDIES: Molecular analysis of the SRD5A2 gene by DNA sequencing of all 5 exons revealed the presence of the splice mutation $A>G$ at position -2 of the acceptor site of intron 1/exon 2 (IVS1-2A>G) in homozygosity. Both non-consanguineous parents were found to be heterozygotes for this mutation. CONCLUSIONS: Although rare, SRD5A2 gene defect should be suspected in any girl presenting with PA and virilisation at puberty. The IVS1-2A $>$ G mutation of the $S R D 5 A 2$ gene predominates in Greek-Cypriot patients with $5 \alpha$-reductase deficiency and very likely reflects a founder effect.
\end{abstract}

Key words: 46,XY disorder of sex development (DSD), $5 \alpha$-reductase, Male pseudohermaphroditism, SRD5A2 gene

Address for correspondence:

Nicos Skordis, MD, Pediatric Endocrine Unit, Dept of Paediatrics, Nicosia 1474, Cyprus, Tel.: +357 22405000, Fax: +357 22305072, e-mail: nskordis@cytanet.com.cy

Received 02-01-11, Revised 02-03-11, Accepted 22-04-11

\section{INTRODUCTION}

Dihydrotestosterone (DHT) is essential for the normal development of male external genitalia. DHT is derived from testosterone $(\mathrm{T})$ by a process catalysed 
by the membrane-bound steroid 5a-reductase enzyme. Impaired DHT synthesis caused by 5alpha steroid reductase deficiency ( $5 \alpha$-reductase deficiency) can lead to incomplete masculinisation of the external genitalia in subjects with a 46,XY karyotype. ${ }^{1}$ The clinical spectrum of a $46, X Y$ individual with $5 \alpha$-reductase deficiency at birth can range from complete female appearance of the external genitalia to nearly complete male phenotype. Most patients, however, present with genital ambiguity and are diagnosed in infancy. At puberty 46,XY patients show virilisation without breast development, often accompanied by gender identity change, from female to male in individuals in whom gonads had not been removed. ${ }^{2-5}$

The enzyme steroid $5 \alpha$-reductase exists as two isoforms, $5 \alpha-\mathrm{R}$ type 1 and $5 \alpha-\mathrm{R}$ type 2 , which have a different expression pattern. Type 1 isoenzyme is encoded by the $S R D 5 A 1$ gene located on chromosome 5 and expressed at low levels in the prostate, whereas type 2 isoenzyme is encoded by the $S R D 5 A 2$ gene that maps on chromosome 2 and is expressed at high levels in the prostate and in many other androgensensitive tissues. ${ }^{6}$

$5 \alpha$-reductase deficiency is caused by mutations in the SRD5A2 gene, whereas the SRD5A1 gene has not been found to be mutated in this disease. To date, 54 different mutations of the SRD5A2 gene have been reported 42 of which are missense/nonsense mutations (http://www.hgmd.cf.ac.uk/ac/gene. php?gene $=S R D 5 A 2)$. Several SRD5A2 mutations have been identified in various populations, while others have only been described in specific ethnic groups. Given the significant advances in understanding the molecular basis of abnormal sexual development, it is important to integrate current knowledge to establish the exact diagnosis in any subject with defects in sexual differentiation.

Although most individuals with $5 \alpha$-reductase deficiency are identified in the neonatal period because of ambiguous genitalia, some are misdiagnosed as androgen insensitivity syndrome, as they often present with the same clinical phenotype, while others escape recognition completely. The current report describes the identification of the IVS1-2A $>\mathrm{G}$ mutation of the SRD5A2 gene in homozygosity in an adolescent girl presented with primary amenorrhea (PA) and virilisation.

\section{CASE PRESENTATION}

A 14-year-old girl of non-consanguineous parents presented with PA and lack of breast development. She was $173 \mathrm{~cm}$ in height, obviously virilised with an increased amount of pubic hair extended to the inner thigh area and clitoromegaly $(3 \mathrm{~cm})$. She also had a deep voice and prominent Adam's apple. Gonads were palpable in the inguinal canal bilaterally. She underwent a gynaecological examination which showed a $4 \mathrm{~cm}$ blind vaginal pouch. No uterus was identified on pelvic ultrasound.

\section{LABORATORY INVESTIGATION AND RESULTS}

Chromosomal analysis showed a normal male $46, \mathrm{XY}$ karyotype. The diagnosis of $5 \alpha$-reductase deficiency was suspected based on biochemical findings at base line and following hCG stimulation test (hCG 3000 Units daily for 3 consecutive days). As shown in Table 1, the patient's Testosterone to DHT ratio (T/DHT) was elevated before (16.6) and further increased after hCG stimulation (29.5). The diagnosis of $17 \beta-H S D-3$, which may have similar clinical presentation, seemed unlikely because of the normal response of androstenedione.

\section{Molecular studies}

The screening for the IVS1-2A $>\mathrm{G}$ mutation in our population previously reported showed a carrier

Table 1. Results of the hCG stimulation test (A) and the GnRH stimulation test (B)

\begin{tabular}{|c|c|c|c|}
\hline \multicolumn{4}{|l|}{$\mathbf{A}$} \\
\hline Hormones & & Before & After \\
\hline Testosterone $\mathrm{nmol} / \mathrm{L}$ & & 18.2 & 32.4 \\
\hline DHEAS nmol/L & & 4838.4 & 5199.4 \\
\hline Androsteredione nmol/L & & 18.5 & 17.5 \\
\hline DHT nmol/L & & 1.10 & 1.10 \\
\hline$\underline{\mathrm{T} / \mathrm{DHT}}$ & & 16.6 & 29.5 \\
\hline \multicolumn{4}{|l|}{ B } \\
\hline Hormones & $\mathbf{0}$ & 30 & 60 \\
\hline FSH IU/L & 10.7 & 17.7 & 20.2 \\
\hline LH IU/L & 6.7 & 49.5 & 49 \\
\hline Estradiol pmol/L & 102.3 & - & - \\
\hline SHBG nmol/L & 24 & - & - \\
\hline
\end{tabular}


rate of $0.98 \%$, or 2 in 204 [95\% Poisson confidence interval (CI), 0.12-3.54\% and/or using the binomial CI, $0.12-3.5 \%]^{7}$

DNA sequencing of all five exons of the $S R D 5 A 2$ gene was carried out in the patient and her parents, as previously described. ${ }^{8}$ Briefly, genomic DNA was subjected to PCR amplification with the forward primer 5' gttaaggcgaaatggcagag 3' and the reverse primer 5'acgaggtcattgcagtaggg 3', which selectively amplify part of intron 1 and exon 2 of the SRD5A2 gene producing a fragment of $382 \mathrm{bp}$. For the detection of the IVS1-2A $>\mathrm{G}$ mutation at the splice junction intron 1/exon 2, BstNI restriction enzyme digest was performed. For confirmation of the identified IVS1-2A $>$ G mutation, direct sequencing was also employed on an automated Beckman Coulter CEQ 2000 sequencer. The IVS1-2A > G mutation of $S R D 5 A 2$ gene was identified in a homozygous state in our patient (Figure 1).

The diagnosis of SRD5A2 was confirmed by molecular studies as indicated above. The subsequent and difficult decision to be made was the possible gender change and consequent maintenance or removal of the gonads. Based on an extensive discussion, genetic counselling and psychological support of the parents, the issue of gender change at this critical age of the patient was not considered appropriate or acceptable. Therefore, gonadectomy was performed with no plastic surgery of the external genitalia at
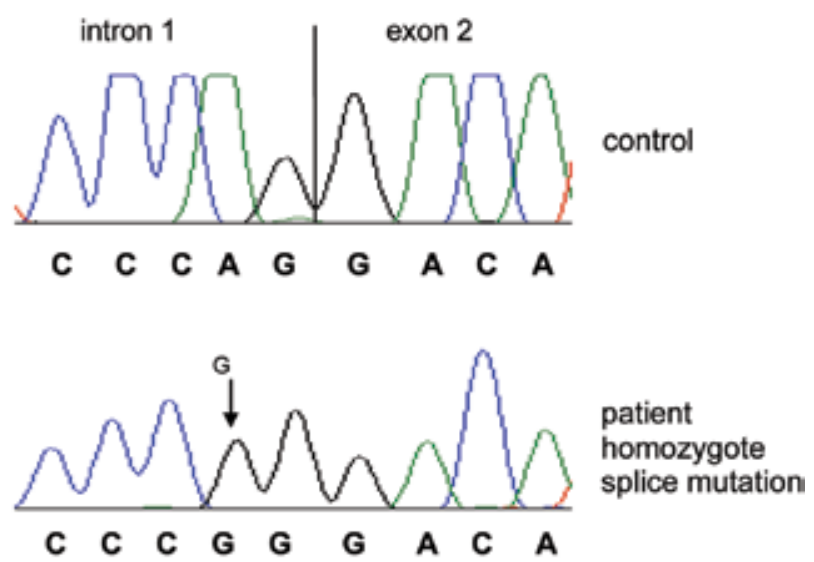

Figure 1. Partial sequence of the intron1/exon2 junction showing the $A$ to $G$ mutation at position -2 of the acceptor splice site. The mutation is homozygous in the patient. A normal control is added. this stage. The patient was subsequently placed on hormonal replacement therapy and she was successfully feminised.

\section{DISCUSSION}

The present report describes the clinical and molecular characteristics of a 14-year-old virilised girl, who presented with PA and was finally diagnosed as a $46, \mathrm{XY}$ individual with $5 \alpha$-reductase deficiency. The typical clinical features in 46,XY males with $5 \alpha$-reductase deficiency are generally those initially reported. ${ }^{4}$ Currently, the diagnosis of $5 \alpha$-reductase deficiency is usually made in the newborn period because most affected individuals present with ambiguous genitalia. ${ }^{9}$ Some children, however, either escape diagnosis or they are misdiagnosed as having partial or complete androgen insensitivity syndrome. The application of molecular testing is a mandatory diagnostic tool for identifying the underlying cause, since biochemical findings in such cases can be misleading. ${ }^{7,10}$ The molecular diagnostic approach using genetic screening of the SRD $5 A 2$ gene permits diagnosis without the need of dynamic testing even in patients who had their testes removed. ${ }^{4}$ If the diagnosis is not made at an early age, the child begins to virilise rather than feminise at puberty if the gonads have not been removed. The clinical signs in the present case are those seen in affected individuals at puberty, namely enlargement of the phallus, virilisation, deepening of the voice, prominent Adam's apple and absence of breast development.

The late diagnosis of affected males with $5 \alpha$-reductase deficiency has been less commonly reported in recent studies compared to earlier publications, in which the majority of the 168 reported cases were diagnosed in infancy or childhood. ${ }^{4,5,8-36}$ Most affected subjects with $5 \alpha$-reductase deficiency presented striking ambiguity of the genitalia with a clitoral-like phallus, severely bifid scrotum, pseudovaginal perineoscrotal hypospadias and a rudimentary prostate. More masculinised individuals lacked a separate vaginal opening or had a blind vaginal pouch which opened into the urethra. Others presented penile hypospadias or even penile urethra. When the genital ambiguity is not very obvious at birth, affected children are raised as females. With the onset 
of puberty the affected males have increased muscle mass and deepening of the voice. ${ }^{37}$

Following discussions and psychological support, the family did not wish a change to a male gender nor did they wish to address this delicate and frustrating issue. Most individuals raised as girls develop a male gender identity and male gender role in adolescence and early adulthood, possibly as a result of pre- and postnatal brain exposure to androgens. ${ }^{36,38}$ The virilisation at puberty is commonly associated with a change in gender role in affected individuals who are not diagnosed in infancy and are raised as girls. A significant number of affected individuals still live as females, although most patients develop a male gender identity in adolescence. The degree of virilisation of the external genitalia at birth does not seem to influence the prevalence of gender role changing. Several factors may determine whether these individuals who were raised as girls will make a switch after puberty. A possible biological factor is the severity of the mutation in terms of the in vivo enzyme deficiency, causing more or less (prenatal) exposure of the brain to androgens. Cultural or other environmental pressures have also been mentioned as potential determinants.

The dilemma of sex reassignment in the present case, where the issue of sexual orientation was purposely not raised, is similar to a previously reported case of an adolescent with 17 $\beta$-HSD-3 deficiency raised as girl. ${ }^{39}$ In that particular case, despite the degree of virilisation of the girl, her manly dressing and behaviour and disturbed emotional status, the final decision following extensive and longtime psychological evaluation was not to proceed to gender change but perform gonadectomy and hormonal replacement therapy, which was obviously successful. Gender role changes are estimated to occur in more than $50 \%$ of cases with $5 \alpha$-reductase deficiency and $17 \beta-H S D-3 .{ }^{40}$ In these two entities the degree of external genital musculinisation at birth does not determine psychosexual outcome. Instead, a masculine appearance in childhood in association with masculine behaviour make a gender role change likely after the pubertal changes reinforce an already existing gender discomfort.

The mutation IVS1-2A $>\mathrm{G}$ of the present patient has also been identified in other Cypriot patients, most likely indicating a founder effect. ${ }^{41}$ Our study in the general population indicates that this is a common mutation in the Cyprus population with an estimated carrier frequency of $0.98 \% .^{7}$ This is further supported by the fact that this mutation has so far been reported at high frequency only in this geographic area. It is therefore speculated that this genetic defect is characteristic in the Eastern Mediterranean area. A study of eight patients from unrelated Turkish families with $5 \alpha$-reductase deficiency revealed the presence of the p.L55Q mutation in six, a finding indicating the increased prevalence of this mutation (hot spot) in the Turkish population. ${ }^{17}$ In a large Lebanese pedigree, where all eight patients were born with unambiguous female genitalia, the same p.L55Q mutation in homozygosity was described.$^{35}$ Other mutations found in Greek-Cypriot patients include p.P181L and p.R171S in compound heterozygosity with the IVS1-2A $>$ G mutation. ${ }^{7}$

In conclusion, $5 \alpha$-reductase deficiency, although rare, should be suspected in any girl presenting with PA and pubertal virilisation and established by molecular analysis of the $S R D 5 A 2$ gene. In patients with $5 \alpha$-reductase deficiency diagnosed so late, as is also the case with $17 \beta-H S D-3$, the management is highly problematic and requires extensive psychological evaluation and support of the patient and his family for the final decision of gender assignment as well a later on. To avoid these complications every effort must be made to establish the underlying molecular defect in every newborn with Disorder in Sexual Development.

\section{Declaration of interest}

The authors declare that there is no conflict of interest that could be perceived as prejudicing the impartiality of the research reported.

\section{Funding}

This work was supported by the A.G. Leventis Foundation, Cyprus.

\section{REFERENCES}

1. Sultan C, Paris F, Terouanne B, et al, 2001 Disorders linked to insufficient androgen action in male children. Hum Reprod Update 7: 314-322. 
2. Mendonca BB, Inacio M, Costa EM, et al, 1996 Male pseudohermaphroditism due to steroid 5alpha-reductase 2 deficiency. Diagnosis, psychological evaluation, and management. Medicine (Baltimore) 75: 64-76.

3. Wilson JD, Griffin JE, Russell DW, 1993 Steroid 5 alpha-reductase 2 deficiency. Endocr Rev 14: 577-593.

4. Imperato-McGinley J, Guerrero L, Gautier T, Peterson RE, 1974 Steroid 5alpha-reductase deficiency in man: an inherited form of male pseudohermaphroditism. Science 186: 1213-1215.

5. Sinnecker GH, Hiort O, Dibbelt L, et al, 1996 Phenotypic classification of male pseudohermaphroditism due to steroid 5 alpha-reductase 2 deficiency. Am J Med Genet 63: 223-230.

6. Jenkins EP, Andersson S, Imperato-McGinley J, Wilson JD, Russell DW, 1992 Genetic and pharmacological evidence for more than one human steroid 5 alphareductase. J Clin Invest 89: 293-300.

7. Skordis N, Neocleous V, Kyriakou A, et al, 2010 The IVS1-2A $>$ G mutation in the SRD5A2 gene predominates in Cypriot patients with 5 Alpha Reductase deficiency. J Endocrinol Invest 33: 510-814.

8. Boudon C, Lobaccaro JM, Lumbroso S, et al, 1995 A new deletion of the 5 alpha-reductase type 2 gene in a Turkish family with 5 alpha- reductase deficiency. Clin Endocrinol (Oxf) 43: 183-188.

9. Bertelloni S, Scaramuzzo RT, Parrini D, Baldinotti F, Tumini S, Ghirri P, 2007 Early diagnosis of 5alphareductase deficiency in newborns. Sex Dev1: 147-151.

10. Walter KN, Kienzle FB, Frankenschmidt A, et al, 2010 Difficulties in diagnosis and treatment of 5alphareductase type 2 deficiency in a newborn with 46,XY DSD. Horm Res Paediatr 74: 67-71.

11. Baldinotti F, Majore S, Fogli A, et al, 2008 Molecular characterization of 6 unrelated Italian patients with 5alpha-reductase type 2 deficiency. J Androl 29: 20-28.

12. Choi JH, Kim GH, Seo EJ, Kim KS, Kim SH, Yoo HW, 2008 Molecular analysis of the AR and SRD5A2 genes in patients with 46,XY disorders of sex development. J Pediatr Endocrinol Metab 21: 545-553.

13. Nicoletti A, Baldazzi L, Balsamo A, et al, A 2005 SRD5A2 gene analysis in an Italian population of under-masculinized 46,XY subjects. Clin Endocrinol (Oxf) 63: 375-380.

14. Vilchis F, Ramos L, Mendez JP, Benavides S, Canto P, Chavez B, 2010 Molecular analysis of the SRD5A2 in $46, X Y$ subjects with incomplete virilization: the P212R substitution of the Steroid 5 \{alpha\}-Reductase- 2 may constitute an ancestral founder mutation in Mexican patients. J Androl 31: 358-364.

15. Vilchis F, Méndez JP, Canto P, Lieberman E, Chávez B, 2000 Identification of missense mutations in the SRD5A2 gene from patients with steroid 5alpha-reductase 2 deficiency. Clin Endocrinol (Oxf) 52: 383-387.

16 Vilchis F, Valdez E, Ramos L, Garcia R, Gomez R, Chavez B, 2008 Novel compound heterozygous mu- tations in the SRD5A2 gene from 46,XY infants with ambiguous external genitalia. J Hum Genet 53: 401-406.

17. Adiyaman PB, Ocal G, Cetinkaya E, et al, 20065 alpha steroid reductase deficiency in Turkey. Pediatr Endocrinol Rev 3: Suppl 3: 462-469.

18. Sahakitrungruang T, Wacharasindhu S, Yeetong P, Snabboon T, Suphapeetiporn K, Shotelersuk V, 2008 Identification of mutations in the SRD5A2 gene in Thai patients with male pseudohermaphroditism. Fertil Steril 90: 2015 e2011-2015.

19. Thigpen AE, Davis DL, Milatovich A, et al, 1992 Molecular genetics of steroid 5 alpha-reductase 2 deficiency. J Clin Invest 90: 799-809.

20. Mazen I, Gad YZ, Hafez M, Sultan C, Lumbroso S, 2003 Molecular analysis of 5alpha-reductase type 2 gene in eight unrelated Egyptian children with suspected 5alpha-reductase deficiency: prevalence of the G34R mutation. Clin Endocrinol (Oxf) 58: 627-631.

21. Bahceci M, Ersay AR, Tuzcu A, Hiort O, Richter-Unruh A, Gokalp D, 2005 A novel missense mutation of 5-alpha reductase type 2 gene (SRD5A2) leads to severe male pseudohermaphroditism in a Turkish family. Urology 66: 407-410.

22. Hiort O, Schutt SM, Bals-Pratsch M, Holterhus PM, Marschke C, Struve D, 2002 A novel homozygous disruptive mutation in the SRD5A2-gene in a partially virilized patient with 5alpha-reductase deficiency. Int J Androl 25: 55-58.

23. Ferraz LF, Mathias Baptista MT, Maciel-Guerra AT, Junior GG, Hackel C, 1999 New frameshift mutation in the 5alpha-reductase type 2 gene in a Brazilian patient with 5alpha-reductase deficiency. Am J Med Genet 87: 221-225.

24. Al-Attia HM, 1997 Male pseudohermaphroditism due to 5 alpha-reductase-2 deficiency in an Arab kindred. Postgrad Med J 73: 802-807.

25. Anwar R, Gilbey SG, New JP, Markham AF, 1997 Male pseudohermaphroditism resulting from a novel mutation in the human steroid 5 alpha-reductase type 2 gene (SRD5A2). Mol Pathol 50:51-52.

26. Can S, Zhu YS, Cai LQ, et al, 1998 The identification of 5 alpha-reductase- 2 and 17 beta-hydroxysteroid dehydrogenase-3 gene defects in male pseudohermaphrodites from a Turkish kindred. J Clin Endocrinol Metab 83: 560-569.

27. Hackel C, Oliveira LE, Ferraz LF, et al, 2005 New mutations, hotspots, and founder effects in Brazilian patients with steroid 5alpha-reductase deficiency type 2. J Mol Med 83: 569-576.

28. Kim SH, Kim KS, Kim GH, Kang BM, Yoo HW, 2006 A novel frameshift mutation in the 5alpha-reductase type 2 gene in Korean sisters with male pseudohermaphroditism. Fertil Steril 85: 750.e9-750.e12

29. Nordenskjold A, Ivarsson SA, 1998 Molecular characterization of 5 alpha-reductase type 2 deficiency and fertility in a Swedish family. J Clin Endocrinol Metab 
83: 3236-3238.

30. Sasaki G, Ogata T, Ishii T, Kosaki K, et al, 2003 Micropenis and the 5alpha-reductase-2 (SRD5A2) gene: mutation and V89L polymorphism analysis in $81 \mathrm{Japa}-$ nese patients. J Clin Endocrinol Metab 88: 3431-3436.

31. Hafez M, Mazen I, Ghali I, Sultan C, Lumbroso S, 2003 A new mutation of 5-alpha-reductase type 2 (A62E) in a large Egyptian kindred. Horm Res 59: 281-284.

32. Savage MO, Preece MA, Jeffcoate SL, et al, $1980 \mathrm{Fa}-$ milial male pseudohermaphroditism due to deficiency of 5 alpha-reductase. Clin Endocrinol (Oxf) 12: 397-406.

33. Boudon C, Lumbroso S, Lobaccaro JM, 1995 Molecular study of the 5 alpha-reductase type 2 gene in three European families with 5 alpha-reductase deficiency. J Clin Endocrinol Metab 80: 2149-2153.

34. Fernández-Cancio M, Rodó J, Andaluz P, et al, 2004 Clinical, biochemical and morphologic diagnostic markers in an infant male pseudohermaphrodite patient with compound heterozygous mutations (G115D/R246W) in SRD5A2 gene. Horm Res 62: 259-264.

35. Hochberg Z, Chayen R, Reiss N, et al, 1996 Clinical, biochemical, and genetic findings in a large pedigree of male and female patients with 5 alpha-reductase 2 deficiency. J Clin Endocrinol Metab 81: 2821-2827.
36. Praveen EP, Desai AK, Khurana ML, et al, 2008 Gender identity of children and young adults with 5alphareductase deficiency. J Pediatr Endocrinol Metab 21: 173-179.

37. Imperato-McGinley J, Zhu YS, 2002 Androgens and male physiology the syndrome of 5alpha-reductase-2 deficiency. Mol Cell Endocrinol 198: 51-59.

38. Cohen-Kettenis PT, Pfäfflin F, 2010 The DSM diagnostic criteria for gender identity disorder in adolescents and adults. Arch Sex Behav 39: 499-513.

39. Liakopoulou M, Keramydas D, Dracopoulou IM, DacouVoutetakis C, 2009 The dilemma of sex reassignment in an adolescent with 17beta-HSD-3 deficiency raised as a female: ten-year follow-up. Arch Sex Behav 38: 615-618.

40. Cohen-Kettenis PT, 2005 Gender change in 46,XY persons with 5alpha-reductase- 2 deficiency and 17 betahydroxysteroid dehydrogenase-3 deficiency. Arch Sex Behav 34: 399-410.

41. Skordis N, Patsalis PC, Bacopoulou I, Sismani C, Sultan C, Lumbroso S, 2005 5alpha-reductase 2 gene mutations in three unrelated patients of Greek Cypriot origin: identification of an ancestral founder effect. J Pediatr Endocrinol Metab 18: 241-246. 